\title{
Biodegradation Kinetics of Phenol, 2,4,6-Trichlorophenol and Pentachlorophenol with ligninolytic enzymes from Dichomitus Squalens
}

\author{
Nastja Zupan, Janja Babič and Aleksander Pavko
}

Faculty of Chemistry and Chemical Technology, University of Ljubljana, 1000 Ljubljana, Slovenia zupan.nastja@gmail.com

janjababic@siol.net

saso.pavko@fkkt.uni-lj.si

\section{ABSTRACT}

Biodegradation of phenol, 2,4,6-trichlorophenol and pentachlorophenol was investigated using Dichomitus squalens cultivation media filtrates with initial laccase and manganese peroxidase activities of $1000 \mathrm{U} \mathrm{L}^{-1}$ and $300 \mathrm{U} \mathrm{L}^{-1}$, respectively. Decomposition of all three biocides was studied at $\mathrm{T}=28^{\circ} \mathrm{C}, \mathrm{pH}=4.5$ and initial concentrations around $6 \mathrm{mg}$ $\mathrm{L}^{-1}$ and the kinetics evaluated on the basis of the time course of the biocide concentration data. Integral analysis revealed $1^{\text {st }}$ order reaction for all three pollutants and the corresponding reaction rate constants and initial concentrations for phenol, 2,4,6-TCP and PCP were estimated from linearized experimental data. The rate equations obtained allow estimation of the times necessary for a particular biocide conversion. The toxicity of reactants and products to the bacterium Vibrio fischeri before and after 48-hours degradation showed that the products were less toxic than the reactants in all three cases. The initial solutions of the three toxic substances caused $54-62 \%$ inhibition of the bacterium Vibrio fischeri, while after 48 hours of degradation, $57 \%$ reduction in the toxicity of phenol, $50 \%$ reduction of $2,4,6$-TCP and $29 \%$ reduction of PCP was achieved.

\section{Keywords}

Biodegradation kinetics; phenol; 2,4,6-trichlorophenol; pentachlorophenol; Dichomitus squalens

\section{Council for Innovative Research}

Peer Review Research Publishing System

Journal: Journal of Advances in Chemistry

Vol. 8, No. 3

editor@cirjac.com

$\underline{\text { www.jac.cirworld.com, member.cirworld.com }}$ 


\section{INTRODUCTION}

White rot fungi have a unique lignin degradation system, which is suitable for elimination not only of lignin from wood but also of various lignin-related pollutants. Because of this non-specific system, white rot fungi have a great potential for degradation of a wide range of environmentally persistent pollutants. For this reason, interest in the degradation of different environmental pollutants with white rot fungi has increased in the last two decades [1].

Phenol is employed in the production of resins and in the manufacture of various chemicals, while halogenated phenols like 2,4,6-trichlorophenol (TCP) and pentachlorophenol (PCP) have been used as wood preservatives and pesticides. Phenolic compounds are hazardous pollutants that are toxic at relatively low concentrations. As they persist in the environment, their accumulation creates toxicity both for flora and fauna. Most fungal degradation studies concerning chlorophenols and other pollutants have been done using Phanerochaete chrysosporium. However, other white rot fung such as Trametes versicolor, Pleurotus ostreatus, Irpex lacteus and others can be used due to their ability to produce high levels of ligninolytic enzymes [2, 3].

Data on the degradation rate of a particular pollutant at given operating conditions is the key parameter for the development and design of removal technology for that harmful chemical $[4,5]$. This type of research increased during the last decade. Bioremediation during microbial cultivation is one of the possible ways of pollutant treatment. Comparison of growth kinetics and phenol metabolizing enzymes has been made with Trichosporon cutaneum and mutants with modified degradation abilities. Using phenol as the sole carbon and energy source, its degradation was successfully described by Haldane-type kinetics [6]. The same kinetic equation also well represented the degradation of a mixture of phenol and resorcinol by Aspergillus Awamori strain [7]. Various white rot fungi, Phanerochaete chrysosporium, Trametes versicolor and Lentinula edodes were used to study the kinetics of degradation of phenol and its chlorinated forms in trickling packed bed reactors, where first order degradation rate constants were determined [8]. Trametes versicolor was used during reactor development for PCP biodegradation. Here, both the Michaelis-Menten model as well as the substrate inhibition model were taken into account to express the PCP degradation rate [9]. A comparison of zero order, first order and Monod kinetic models was made to fit the experimental data for continuous aerobic biodegradation of phenol with immobilized mixed bacterial and fungal culture on various packing materials in a packed bed reactor [10]. The enzyme production activity of $P$. chrysosporium and degradation of PCP during microbial growth in a packed bed bioreactor was studied and a mineralization ratio exceeding $80 \%$ was achieved [11]. During field-scale bioremediation of PCP by Trametes versicolor, residues of this pollutant declined according to first order kinetics [12]. [13] studied the transformation of 2,4,6-TCP by the rot fungi Panus tigrinus and Coriolus versicolor during growth in submerged cultures. The enzymes involved in degradation were Lac (C. versicolor) and MnP ( $P$. tigrinus), which degraded $90 \%$ of the initial $50 \mathrm{ppm}$ of TCP in $24 \mathrm{~h}$ at $\mathrm{T}=30^{\circ} \mathrm{C}$. The study was oriented towards toxicity effects and no data about reaction kinetics was given.

Isolated enzymes or crude enzyme preparations obtained from cultivation media can also be used for bioremediation purposes. A comprehensive model was developed to describe the kinetics of the oxidation of phenol with laccase from T.versicolor. Here enzyme kinetics, enzyme inactivation, variable reaction stoichiometry between phenol as substrate and oxygen, and oxygen mass-transfer were incorporated in the model [14]. Degradation of several chlorophenols by commercially available laccase was studied and a first-order reaction for 2,4-DCP degradation reported. The authors suggested the use of immobilized enzymes because of their good stability excellent reuse ability [15]. The crude enzyme solution from Phanerochaete crysosporium cultures was used to study the kinetics of PCP degradation. A complex reaction scheme and kinetic model were proposed and the reaction rate constants estimated [16]. The reaction of PCP with laccase from Coriolus versicolor showed Michaelis-Menten kinetics [17]. The oxidation of phenol and polyphenolic compounds using aqueous extracts of the mushroom Agaricus bisporus residual culture compost medium was studied. Considering laccase as the active enzyme, the phenol reduction rate decreased proportionately to the phenol concentration indicating first order kinetics [18]. The treatment of chlorophenols was investigated with laccase immobilized on sol-gel-derived silica. The equation for the kinetics for degradation was obtained, where intraparticle diffusion was taken into account, whereas external diffusion was not important [19]. For a critical evaluation of the process, various toxicity tests before and after degradation are usually performed, since the degradation products can be more toxic than the initial compound. The test with Vibrio fischeri has become very popular in the case of waste waters, because of its good sensitivity [20].

In the last decade, Dichomitus squalens gained importance in studies of synthetic dye decolourization caused by laccases (Lac) and manganese peroxidases (MnP) [21, 22, 23, 24]. However, the bioremediation potential of this fungus for degradation of other environmental pollutants like phenols and chlorinated phenols has not yet been studied. In the present work, the degradation kinetics of phenol and two chlorophenols (TCP and PCP) was investigated with the culture filtrate of Dichomitus squalens and the degradation rate equations were obtained. To obtain better insight into the degradation process and its efficiency, the effect of degradation on Lac and MnP enzyme activities was evaluated, as well as performing toxicity tests before and after 48 hours of degradation.

\section{MATERIALS AND METHODS}

\section{Microorganism and cultivation conditions}

The fungus strain Dichomitus squalens Reid 750 was obtained from the CCBAS culture collection (Institute of Microbiology ASCR, Prague, Czech Republic). The strain was maintained on $2 \%$ malt extract agar (MEA) at $4{ }^{\circ} \mathrm{C}$ as described previously (A16). 
A mycelial suspension and shaken cultures of $D$. squalens were prepared using natural lignin inducer in the form of $0.125-$ $0.3 \mathrm{~mm}$ beechwood particles, as previously described by [24]. D. squalens biomass was grown for up to 12 days in a rotary shaker (RVI-403, Tehnica, Slovenia) at $28{ }^{\circ} \mathrm{C}$ at a constant agitation rate of $150 \mathrm{rpm}$. When high enough enzyme activities were obtained, the biomass was separated from the growth medium by filtration through a black ribbon filter (Macherey-Nagel, USA) and the crude enzyme filtrate with enzymes used for degradation studies.

\section{Preparation of phenol, TCP and PCP stock and reactant solutions}

Stock solutions of phenol, TCP and Na-pentachlorophenolate (NaPCP) were prepared in a mixture of methanol and miliQ water $(50: 50(\mathrm{v} / \mathrm{v}))$ in conentrations of $1 \mathrm{~g} \mathrm{~L}^{-1}$ of phenol and TCP, and $2 \mathrm{~g} \mathrm{~L}^{-1}$ for NaPCP and stored in the dark until use. TCP, PCP and methanol (Sigma-Aldrich (USA)) were of high purity (>98\%). Stock solutions were used for the preparation of reactant solutions with appropriate initial concentrations by dilution. The PCP reactant solution was prepared by dilution of NaPCP stock solution with milliQ water and acidification with phosphoric acid at $\mathrm{pH}=3$.

\section{Degradation of phenol, TCP and PCP}

Degradation studies were done in $250 \mathrm{ml}$ Erlenmeyer flasks containing $100 \mathrm{ml}$ of enzyme filtrate with a Lac activity of $1000 \mathrm{U} \mathrm{L}^{-1}$, obtained from the crude enzyme filtrate by dilution to ensure an equal initial enzyme activity in all experiments. Separate experiments, each in duplicate, were run for each polutant. Phenol, TCP and PCP reactant solutions were added to the Erlenmeyer flasks to obtain an initial concentration $5.5-6.0 \mathrm{mg} \mathrm{L}^{-1}$. The degradation was performed in flasks on a rotary shaker at $28^{\circ} \mathrm{C}$ at a constant agitation rate of $150 \mathrm{rpm}$. The reaction medium samples were collected for HPLC quantification and the toxicity test.

\section{Phenol, TCP and PCP quantification by HPLC analysis}

Reaction medium samples containing phenol, TCP and PCP were centrifuged for 10 min at $4000 \mathrm{rpm}$ and then each filtered through a $0.45 \mu \mathrm{m}$ filter (Millipore 150 / PK). Then solid phase extraction with Strata ${ }^{\text {TM }}-X$ (Phenomenex, USA) was used, following the method described in the Strata ${ }^{\mathrm{TM}}-\mathrm{X}$ manufactures' guide. Extraction started by conditioning the column with HPLC grade methanol $(99 \%)$ and miliQ water, then bonding the target compound on the solid phase, followed by eluting the aqueous compounds with a $5 \%$ solution of methanol in milliQ water. Finally elution of the target compound was done with mixed acetonitrile and methanol in 50:50 (v/v) ratio. The extraction recovery of phenol, TCP and PCP was better than $95 \%$. Their extracts were injected on a Varian Prostar HPLC system with a Prostar Chromatography Workstation using a Gemini-NX C18 $150 \mathrm{~mm}$ column (Phenomenex, USA) at room temperature. Mobile phase A (methanol and acetonitrile in the ratio 50:50 (v/v)) and mobile phase B (miliQ water acidified with acetic acid (3\% (v/v)) were used for gradient elution at a flow rate at $0.8 \mathrm{~mL} \mathrm{~min}^{-1}$. Elution started by mixing phase $A$ and $B$ in the ratio $40: 60$ for 1 minute, then phase $A$ was increased to $100 \%$ in 10 minutes and held constant for 20 minutes and finally returned to the initial mixture of phase A and B in 1 min. Peaks were detected by a UV/Vis detector coupled to the HPLC at $280 \mathrm{~nm}$ [25]. Quantification was done using standard curves obtained with phenol, TCP and PCP standard solutions.

\section{Enzyme analysis}

Laccase (Lac) activity was measured by monitoring the oxidation of $5 \mathrm{mM}$ 2,2'-azino-bis(3-ethylbenzothiozoline-6-sulfonic acid) (ABTS) as increased absorbance at $420 \mathrm{~nm}$ [26], and manganese peroxidase (MnP) activity by monitoring the oxidation of $20 \mathrm{mM}$ 2,6-dimethoxyphenol (DMP) at $469 \mathrm{~nm}$ [27]. One unit of enzyme activity was defined as the amount of the enzyme oxidizing $1 \mu \mathrm{mol}$ of the corresponding substrate per minute. All spectrophotometric measurements were carried out using a Perkin Elmer spectrophotometer (Lambda 25, Hewlett Packard, USA). The substrates for the Lac and MnP activity assays were both purchased from Sigma (USA).

\section{Toxicity test before and after phenol, TCP and PCP degradation}

Phenol, TCP and PCP toxicities before and after degradation were measured using standard tests with the freeze-dried luminescent bacterium Vibrio fischeri, purchased from DR. Lange, GmbH (Dusseldorf, Germany), by bioluminescence inhibition assay. Prior to the test, bacteria were rehydrated using the corresponding reactivation solution provided by the manufacturer. The $30 \mathrm{~min}$ standard bioluminescence inhibition assay was carried out according to [26]. The bacterial suspension and the prepared dilution series of selected compounds were thermostatted in a thermoblock to $15 \pm 0.1{ }^{\circ} \mathrm{C}$ before testing. The aqueous dilution series was applied to the bacterial suspension in the ratio 1:1. Bioluminescence was measured in a luminometer (LUMISTOX, DR. Lange, Germany) just before substance application and after 30 min incubation time in the standard bioluminescence assay.

\section{RESULTS AND DISCUSSION}

This investigation was divided into two parts; production of $D$. squalens ligninolytic enzymes was done first and then the enzymes obtained were used for degradation of phenol, TCP and PCP. Since these compounds can be toxic to fungi [28], only the enzyme filtrate and not the whole fungal broth from cultivation was used for the degradation study. The results of enzyme synthesis in the presence of small beechwood particles, acting as an inducer, are shown in Figure 1. In accordance with our previous study, high enzyme activities were obtained from the enzyme synthesis [24]. Lac and MnP were not isolated, but the crude enzyme filtrate was used because of the possibility of the two enzymes working cooperatively [23, 5]. The production of ligninolytic enyzmes (Lac and MnP) was followed for 14 days. However, after 8-10 days of cultivation when Lac and MnP activities were around $1400 \mathrm{U} \mathrm{L}^{-1}$ and $200 \mathrm{U} \mathrm{L}^{-1}$, respectively, filtrates were collected and used for degradation purposes. 


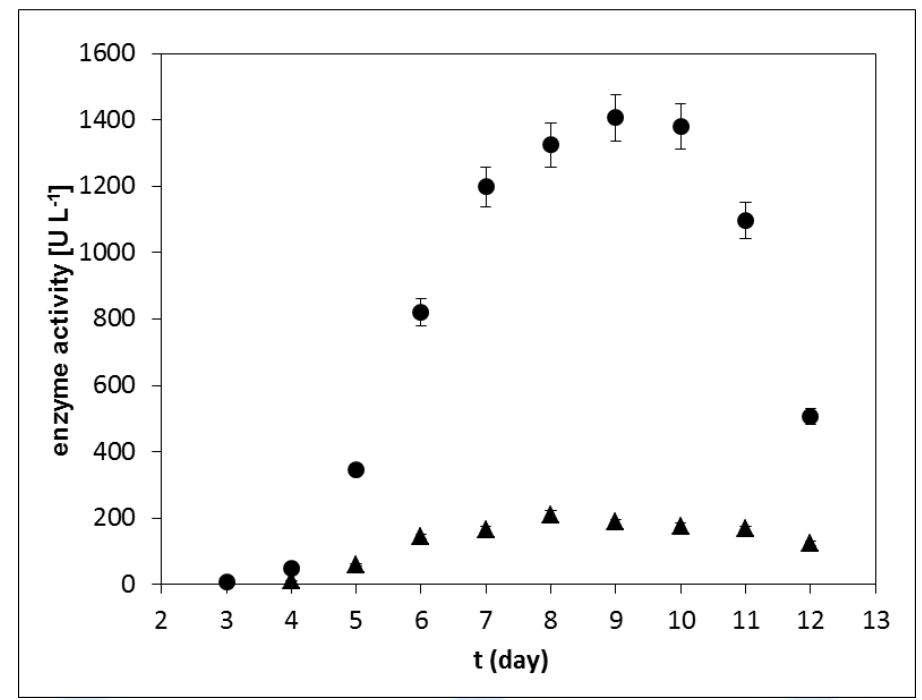

Figure 1. The production of ligninolytic enzymes (Lac $\bullet$ and MnP $\Delta$ ) in submerged cultures with the addition of 0.125-3.0 mm particles of beechwood as a natural lignin inducer. Experiments were done in a rotary shaker at 150 $\mathrm{rpm}, \mathrm{T}=28^{\circ} \mathrm{C}$ and $\mathrm{pH}=4.5$. All data points are the mean values of duplicate flask samples with an average deviation of $+/-5 \%$.

Degradation of all three pollutants was studied at concentrations below $6 \mathrm{mg} \mathrm{L}^{-1}$ where they are soluble in water at room temperature. In all cases it was assumed that the degradation rate in $\mathrm{mg} \mathrm{L}^{-1} \mathrm{~h}^{-1}$ is proportional to the conentration of the

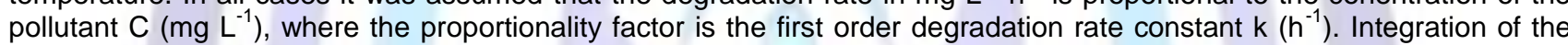
differential rate expression with initial concentration $\mathrm{C}_{0}$ at the beginning of the experiment $(t=0)$ gives the concentration profile expression [8].

$$
\mathrm{C}=\mathrm{C}_{0} \exp (-\mathrm{kt})
$$

Linearization of data points was done by plotting the natural logarithm of concentration vs. time. The slope of the line corresponds to the first order reaction rate constant $\mathrm{k}$ and the intercept is proportional to the initial concentration $\mathrm{C}_{0}$ [4]. The experimental data points from a 48 hour degradation of phenol at $28{ }^{\circ} \mathrm{C}$ and $\mathrm{pH} 4.5$, as well as the degradation curve considering Equation 1, are presented together in Figure 2. The estimated first order reaction constant and initial concentration for phenol are $\mathrm{KPH}_{\mathrm{PH}}=0.059 \mathrm{~h}^{-1}$ and $\mathrm{C}_{0}=5.9 \mathrm{mg} \mathrm{L}^{-1}$. These data allow estimation of phenol concenration depletion as a function of time using equation 1. Initial Lac and MnP activities were around 1000 and $300 \mathrm{U} \mathrm{L}^{-1}$ and at the end of the experiment they decreased to 400 and $200 \mathrm{UL}^{-1}$, respectively (data not shown). We assumed that these enzyme activities were still high enough to enable degradation and inhibition was not considered. These results of successful phenol degradation are in agreement with those of [18]. They used aqueous extracts of residual compost for phenol degradation, where Lac $\left(200 \mathrm{U} \mathrm{mL}^{-1}\right)$ was identified as the main enzyme activity and proposed a first order degradation rate expression. Using much higher concentrations of phenol $1 \mathrm{mg} \mathrm{mL}^{-1}$ and $5 \mathrm{mg} \mathrm{mL}^{-1}$ and enzyme activities compared to our investigation, they achieved total degradation at $25^{\circ} \mathrm{C}$ and $\mathrm{pH} 7.0$ in $48 \mathrm{~h}$ and $125 \mathrm{~h}$, respectively. Also [8] succeeded in almost completely degrading phenol in a trickling packed bed reactor with immobilized white-rot cultures at an initial concentration of $800 \mathrm{mg} \mathrm{L}^{-1}$ in $24-30 \mathrm{~h}$ batch cycles. They reported a first order rate constant for phenol degradation of $0.2 \mathrm{~h}^{-1}$ and a lignin peroxidase activity around $18 \mathrm{U} \mathrm{L}^{-1}$. 


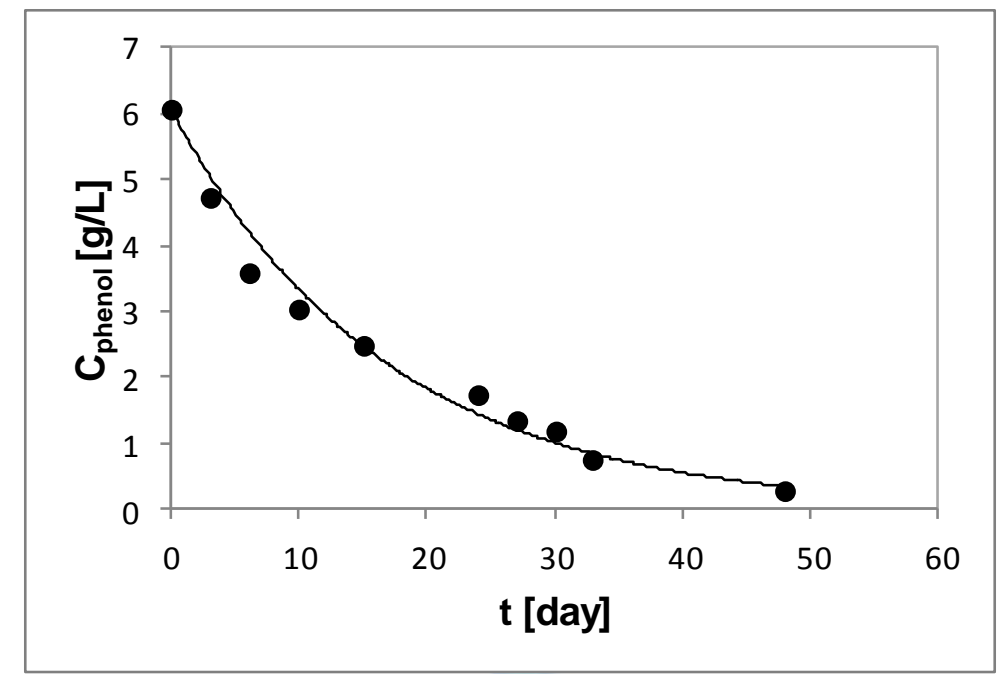

Figure 2. Decrease of phenol ( $\downarrow$ ) concentration in enzyme filtrate medium with initial Lac and MnP activities of 1000 and $130 \mathrm{U} \mathrm{L}^{-1}$, respectively, at $\mathrm{T}=28^{\circ} \mathrm{C}, \mathrm{pH}=4.5$ and agitation at $150 \mathrm{rpm}$. All data points are the mean values of duplicate flask samples with an average deviation of $+/-5 \%$, while the curve represents the results calculated using the kinetic equation obtained.

The successful degradation of 2,4,6-TCP is shown in Figure 3 where both experimental points and predicted results in the form of a curve are given. The initial $5.6 \mathrm{mg} \mathrm{L}^{-1} \mathrm{TCP}$ concentration decreased to $60 \%$ in $12 \mathrm{~h}$ and reached a concentration below $1 \mathrm{mg} \mathrm{L}^{-1}$ after $24 \mathrm{~h}$. The 2,4,6-TCP degradation rate can also be described as first order reaction with a degradation rate constant $\mathrm{k}_{\mathrm{TCP}}=0.08 \mathrm{~h}^{-1}$ and an initial concentration $\mathrm{C}_{0}=5.6 \mathrm{mg} \mathrm{L}^{-1}$. Similarly to phenol experiments, initial Lac and $\mathrm{MnP}$ activities were around 1000 and $300 \mathrm{U} \mathrm{L}^{-1}$ and at the end 400 and $200 \mathrm{U} \mathrm{L}^{-1}$, respectively (data not shown). First order degradation kinetics was also found in the [8] where besides phenol the degradation of 2,4,6-TCP was also studied in a trickling packed bed reactor with immobilized white-rot culture. A degradation rate constant for $2,4,6-\mathrm{TCP}$ of $0.3 \mathrm{~h}^{-1}$ at a lignin peroxidase activity of around $18 \mathrm{U} \mathrm{L}^{-1}$ was reported.

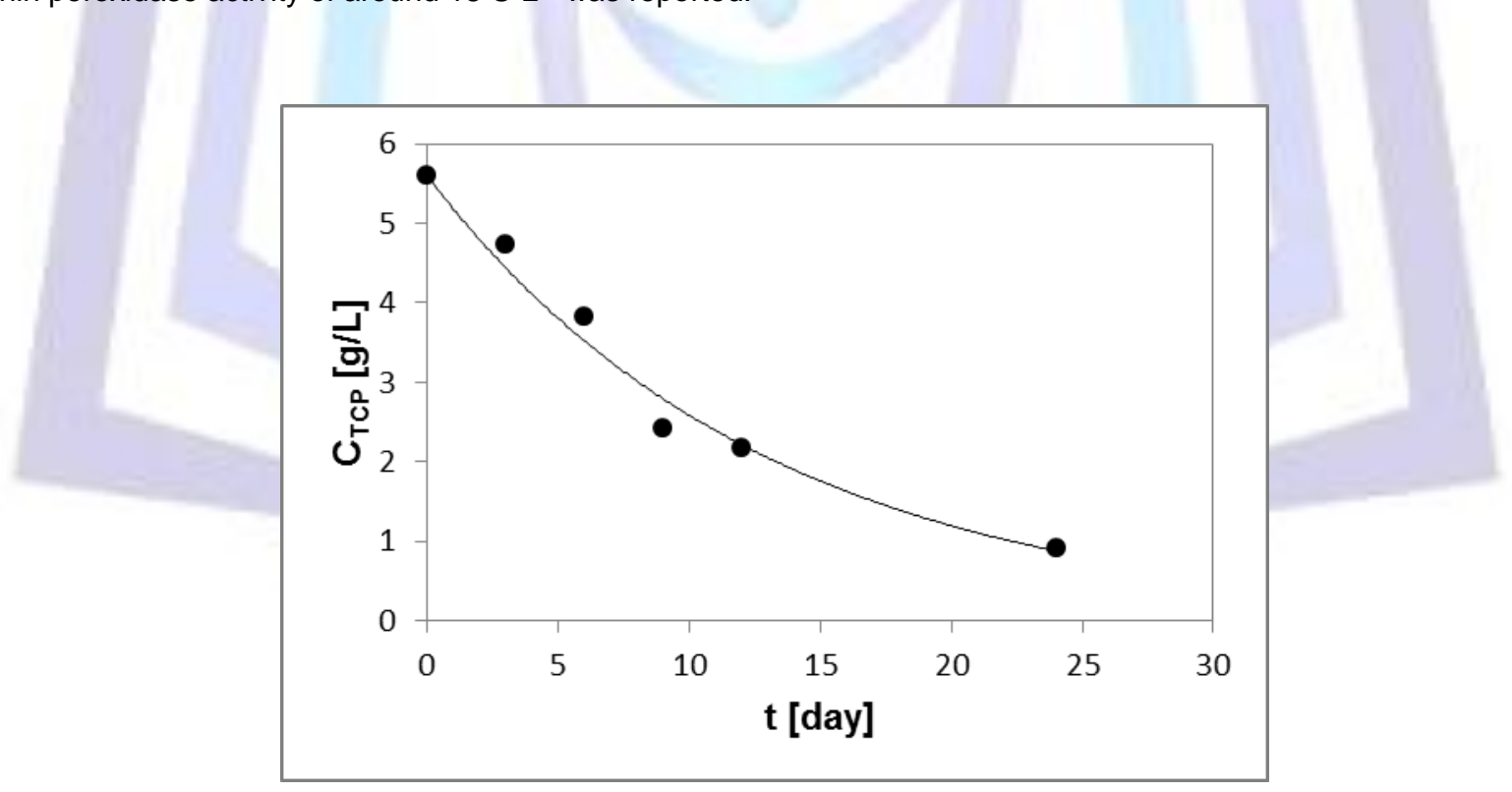

Figure 3. Decrease of 2,4,6-TCP $(\bullet)$ concentration in enzyme filtrate medium with initial Lac and MnP activities of 1000 and $130 \mathrm{U} \mathrm{L}^{-1}$ at $\mathrm{T}=28{ }^{\circ} \mathrm{C}, \mathrm{pH}=4.5$ and agitation at $150 \mathrm{rpm}$. All data points are means of duplicate samples from shaken flask studies. The average deviation from the mean values of the data points is $+/-5 \%$, while the curve represents the results calculated results using the kinetic equation obtained. 
The results of the PCP degradation study are shown in Figure 4. Experimentally it was found that the concentration of PCP decreased from an initial $5.8 \mathrm{mg} \mathrm{L}^{-1}$ by $76 \%$ in $24 \mathrm{~h}$ and reached a concentrations below $1 \mathrm{mg} \mathrm{L}^{-1}$ after $32 \mathrm{~h}^{-}$ Considering this data, the estimated first order degradation rate constant and initial concentration are $\mathrm{K}_{\mathrm{PCP}}=0.08 \mathrm{~h}^{-1}$ and $\mathrm{C}_{0}=5.4 \mathrm{mg} \mathrm{L}^{-1}$, respectively, where the degradation curve is shown in the same figure. The enzyme activities decreased from initial values for $\mathrm{Lac}$ and $\mathrm{MnP}$ of 1000 and $300 \mathrm{U} \mathrm{L}^{-1}$ to 700 and $200 \mathrm{U} \mathrm{L}^{-1}$, respectively, at the end of the degradation experiment.

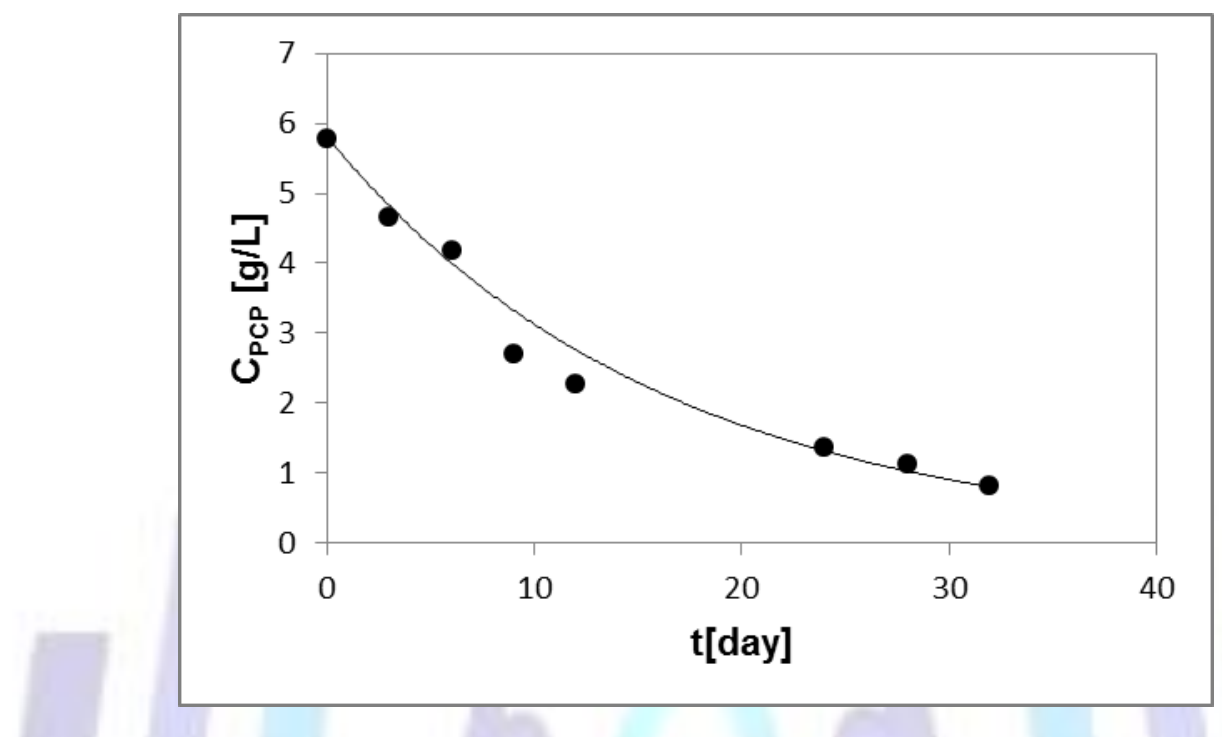

Figure 4. Decrease of TCP $(\diamond)$ concentration in enzyme filtrate medium with initial Lac and MnP activities of 1000 and $130 \mathrm{U} \mathrm{L}^{-1}$ at $\mathrm{T}=28^{\circ} \mathrm{C}, \mathrm{pH}=4.5$ and agitation at $150 \mathrm{rpm}$. All data points are the mean values of duplicate flask samples with an average deviation of $+/-5 \%$, while the curve represents the results calculated using the kinetic equation obtained.

Lac from the fungus $C$. versicolor has been used in PCP degradation studies [17]. The reaction of PCP with 100 units of laccase showed Michaelis-Menten kinetics in the PCP range of $20-200 \mu \mathrm{g} \mathrm{mL}{ }^{-\dagger}$ at $25^{\circ} \mathrm{C}$ and pH 5 , and $60-100 \%$ removal was achieved between 24-72 hours. [16] studied the degradation of PCP with various mixtures of extracellular enzymes and cell mass (cell-bound enzymes) of $P$. chrysosporium. They proposed a parallel-series first order reaction for initial PCP concentrations lower than $12 \mu \mathrm{mol} \mathrm{L}^{-1}$, when up to $70 \%$ PCP degradation was achieved.

In all three degradation studies, a decrease of $\mathrm{Lac}$ and MnP activities was observed. Peroxidases like MnP catalyse the oxidation of phenolic substances, leading to the formation of reactive free radicals. They can form water insoluble polymers with enyzme binding sites, which can cause an enzyme activity decrease and even total deactivation of the enzyme [29]. Some improvements like immobilization of the enzymes or usage of enzyme mediators such as ABTS, TEMPO or HBT can be considered to gain better enzyme stability in the degradation process [30, 13]).

The results of this investigation together with the predicted times for various reactant conversions are collected in Table 1. Comparison between the three pollutants shows that under the investigated conditions, degradation of 2,4,6-TCP is the fastest, while the degradation rate of phenol and PCP does not vary much.

Table 1. Reaction rate parameters for the prediction of pollutant concentrations using Equation 1 and estimated degradation times for 50 and $90 \%$ conversion.

\begin{tabular}{|l|l|c|l|c|c|}
\hline Reactant & $\mathrm{k}\left(\mathrm{h}^{-1}\right)$ & $\mathrm{C}_{0}\left(\mathrm{mg} \mathrm{L}^{-1}\right)$ & $\mathrm{R}^{2}$ & $50 \%$ degradation $(\mathrm{h})$ & $90 \%$ degradation $(\mathrm{h})$ \\
\hline phenol & 0.059 & 5.9 & 0.98 & 10 & 39 \\
\hline $2,4,6-\mathrm{TCP}$ & 0.079 & 5.6 & 0.98 & 9 & 29 \\
\hline PCP & 0.060 & 5.4 & 0.98 & 12 & 38 \\
\hline
\end{tabular}

The results of the toxicity experiments with the bioluminescent bacterium Vibrio fischeri are shown in Figure 5 . The influence of the initial biocide concentration or mixture of intermediate compounds formed during degradation is presented as bioluminescence inhibition. The initial concentrations of all three biocides caused inhibition of $V$. fischeri bioluminescence in the range from $54 \%(\mathrm{TCP})$ to $62 \%(\mathrm{PCP})$ (grey columns, $\mathrm{t}=0 \mathrm{~h}$ ). After $48 \mathrm{~h}$ of biocide degradation 
the mixture of different degradation intermediates generated and the results of their inhibition for each biocide are shown by black columns. The solution with phenol degradation products, where the initial amount of phenol was reduced by more than $90 \%$, inhibited only $25 \%$ of $V$. fischeri bioluminescence. A similar effect on bioluminescence inhibition was also found with 2,4,6-TCP degradation products. Inhibition after $48 \mathrm{~h}$ of degradation was twice as small (27\%) compared to the initial inhibition effect of 2,4,6-TCP (54\%). The highest inhibition was found with PCP products (44\%), where an important reduction of the toxic effect on Vibrio fischeri due to enzymatic degradation was found. The products of ligninolytic enzyme action caused the highest reduction in toxicity during phenol degradation (57\%) and the lowest toxicity reduction in PCP degradation $(29 \%)$. The products of partial degradation or transformation of a pollutant can display lower toxicity than the original compound. [31] reported that a crude laccase extract from the white rot fungus $T$. pubescens caused a reduction in concentration and toxicity of a mixture of chlorophenols, also containing 2,4,6-TCP and PCP. Phenol can be transformed to catechol and hydroquinone with minor toxic effects. [32]. Elimination of $\mathrm{Cl}$ from chlorophenols can lead to less toxic benzoquinones [33,34]), since the toxicity increases with the number of $\mathrm{Cl}$ atoms on the benzene ring [35]. Our results agree with these literature data.

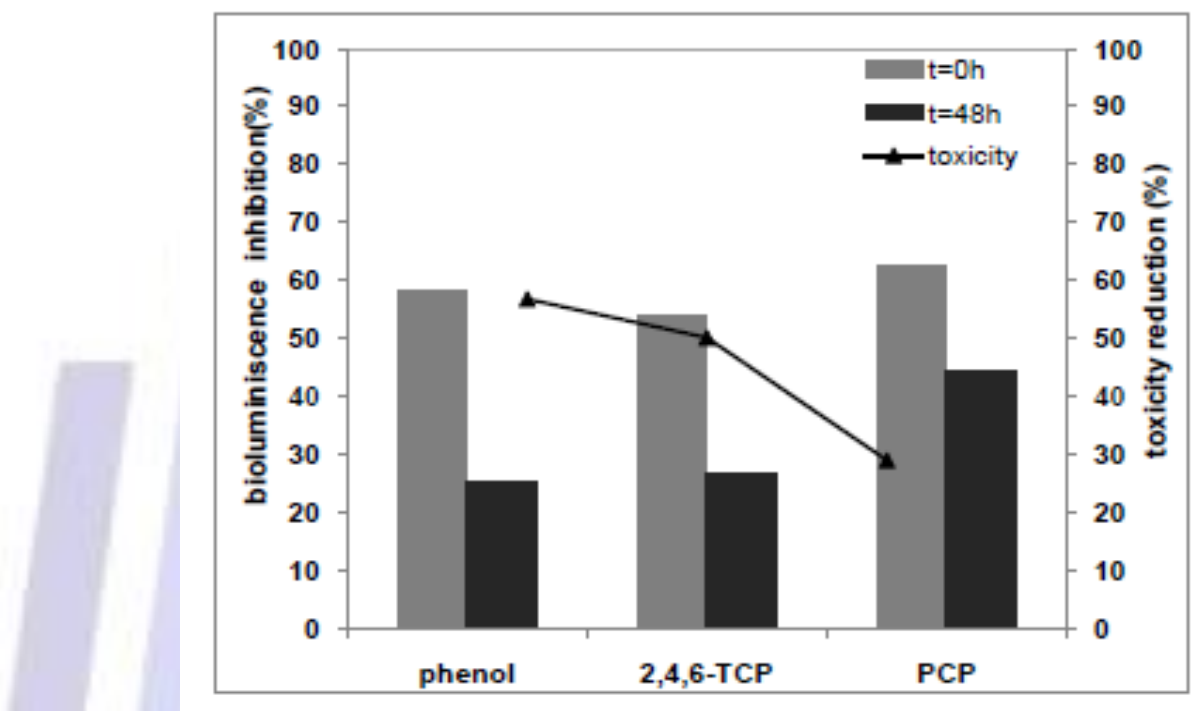

Figure 5. Toxicity of phenol, 2,4,6-TCP and PCP reaction solutions to the bacterium Vibrio fischeri after enzymatic degradation. All data points are means of duplicate samples.

\section{CONCLUSIONS}

The results of this investigation confirm the applicability of ligninolytic enzymes in the bioremediation technology of organic pollutants. The enzymatic activity test showed that the enzymatic activity decreased but was high enough to allow reaction throughout the experiment. Phenol, 2,4,6-trichlorophenol and pentachlorophenol were successfully removed from water solutions. Chemical reaction engineering aspects of their enzymatic biodegradation were successfully applied to obtain the kinetic rate equations. This allowed the prediction of a particular pollutant depletion in its water solution, that is estimation of the times necessary for a particular biocide conversion. In addition, comparison of the toxicity of reactants and products showed that the products were less toxic than the reactants in all three cases.

The presented approach can be readily utilized for a wide range of other pollutants for predicting rate equations and consequently the times necessary for their removal from waste waters to below the allowed concentrations. If the analytical equipment is available, the identification of degradation products would enrich the research data. Furthermore, it was shown that toxicity tests are necessary for process evaluation. All this information could be used for the estimation of purification costs.

\section{Acknowledgement}

The authors would like to thank the Slovenian Research Agency for financial support. 


\section{REFERENCES}

[1] Reddy, C. A. and Mathew, Z. 2001. Bioremediation potential of white rot fungi. In: Fungi in bioremediation. G.M. Gadd. (Editor). Cambridge University Press, Cambridge: 52-78.

[2] Singh, H. 2006. Fungal Metabolism of Phenols, Chlorophenols and Pentachlorophenol. In: Mycoremediation. Fungal Bioremediation. Wiley Interscience, Hoboken: 215-282

[3] Rubilar, O., Diez, M. C., Gianfreda, L. 2008. Transformation of Chlorinated Phenolic Compounds by White Rot Fungi, Crit. Rev. Environ. Sci. Techno. 38 (4), 227-268.

[4] Levenspiel, O. 1999. Chemical reaction Engineering, $3^{\text {rd }}$ Ed., John Wiley and Sons, New York, 1-89.

[5] Pavko, A. 2011. Fungal Decolourization and Degradation of Synthetic Dyes. Some Chemical engineering Aspects. In: Waste Water - Treatment and Reutilization. Fernando S. Garcia Einschlag (Editor). InTech, Rijeka: 65-88.

[6] Alexievaa, Z., Gerginova, M., Zlateva, P. and Peneva, N. 2004. Comparison of growth kinetics and phenol metabolizing enzymes of Trichosporon cutaneum R57 and mutants with modified degradation abilities. Enzyme and Microbial Technology 34, 242-247.

[7] Yemendzhiev, H., Zlateva, P., Terziyska, A. and Alexieva Z. 2010. Phenol and resorcinol mixture degradation by Aspergillus awamori strain. Comptes rendus de l'Acad'emie bulgare des Sciences 63 (11), 1577-1582.

[8] Ehlers, G.A. and Rose, P.D. 2005. Immobilized white-rot fungal biodegradation of phenol and chlorinated phenol in trickling packed-bed reactors by employing sequencing batch operation. Bioresource Technology 961, $264-$ 1275.

[9] Pallerla, S. and Chambers, R. P. 1998. Reactor development for biodegradation of pentachlorophenol. Catalysis Today $40,103-111$

[10] Gerrard, A. M., Júnior, J. P., Kostečková, A., Páca, J., Stiborová M. and C. R. Soccol. 2006. Simple Models for the Continuous Aerobic Biodegradation of Phenol in a Packed Bed Reactor. Brazilian archives of Biology and Technology 49 (4), 669-676.

[11] Shim, S.-S. and Kawamoto, K. 2002. Enzyme production activity of Phanerochaetel chrysosporium and degradation of pentachlorophenol in a bioreactor. Water Research 36 (18), 4445-4454.

[12] Walter, M., Boyd-Wilson, K., Boul, L., Ford, C., McFadden, D., Chong, B., and Pinfold, J. 2005. Field-scale bioremediation of pentachlorophenol by Trametes versicolor. International Biodeterioration and Biodegradation $56,51-57$.

[13] Leontievsky, A.A., Myasoedova, N.M., Baskunov, B.P., Evans C.S. and Golovleva, L.A. 2000. Transformation of 2,4,6-trichlorophenol by the white rot fungi Panus tigrinus and Coriolus versicolor. Biodegradation 11, 331-340.

[14] Kurniawati S. and Nicell, J. A. 2009. A Comprehensive Kinetic Model of Laccase-Catalyzed Oxidation of Aqueous Phenol. Biotechnol. Prog. 25 (3), 763-773.

[15] Zhang, J., Liu, X., Xu, Z., Chen, H. and Yang, Y. 2008. Degradation of chlorophenols catalyzed by laccase. International Biodeterioration and Biodegradation 61, 351-356.

[16] Lin, J.-E., Wang, H. Y. and Hickey, R. F. 1990. Degradation kinetics of pentachlorophenol by Phanerochaete chrysosporium. Biotechnology and Bioengineering 35, 1125-1134.

[17] Ullah, M. A., Bedford, C. T. and Evans, C. S. 2000. Reactions of pentachlorophenol with laccase from Coriolus versicolor. Appl. Microbiol. Biotechnol. 53, 230-234.

[18] Trejo-Hernandez, M.R., Lopez-Munguia, A. and Ramirez, R. Q. 2001. Residual compost of Agaricus bisporus as a source of crude laccase for enzymic oxidation of phenolic compounds. Process Biochemistry 36, 635-639.

[19] Quu, L. and Huang, Z. 2010. The treatment of chlorophenols with laccase immobilized on sol-gel-derived silica. World J. Microbiol. Biotechnol. 26, 775-78.

[20] Keddy C. J., Greene J. C. and Bonnell M. A. 1995. Review of whole-organism bioassays: soil, freshwater sediment, and freshwater assessment in Canada. Ecotoxicology and Environmental Safety 30 (3), $221-25$.

[21] Eichlerová, I., Homolka, L., Nerud, F. Synthetic dye decolorization capacity of white rot fungus Dichomitus squalens. Bioresource Technology 97 (16), 2153-2159.

[22] Šušla, M., Novotny, Č. and Svobodova, K. 2007. The implication of Dichomitus squalens laccase isoenzymes in dye decolorization by immobilized fungal cultures. Bioresource technology 98, 2019-2115.

[23] Šušla, M., Novotny, Č., Erbanova, P. and Svobodova, K. 2008. Implication of Dichomitus squalens ManganeseDepoandent Peroxidase in Dye Decolorization and Cooperation of the Enzyme with Laccase. Folia Microbiol. 53 (6), 479-485. 
[24] Babič, J. and Pavko, A. 2012. Enhanced enzyme production with the pelleted form of $D$. squalens in laboratory bioreactors using added natural lignin inducer. Journal of industrial microbiology and biotechnology 39 (3), 449 457.

[25] De Jesus, A. G., Romano-Baez, F. J., Leyva-Amezcua, L., Juarez-Ramirez, C., Ruiz-Ordaz, N., Galindez-Mayer, J. 2009. Biodegradation of 2,4,6-trichlorophenol in a packed-bed biofilm reactor equipped with an internal net tube riser for aeration and liquid circulation. J. of hazardous materials 161, 1140-1149.

[26] ISO 11348-3. 2007. Water Quality-Determination of the Inhibitory Effect of Water Samples on the Light Emission of Vibrio fischeri (Luminescent Bacteria Test). Part 3: Method Using Freeze-dried Bacteria, Geneve.

[27] Tavčar, M., Svobodová, K., Kuplenk, J., Novotný, Č. and Pavko, A. 2006. Biodegradation of azo dye RO16 in different reactors by immobilized Irpex lacteus. Acta Chim. Slov. 53 (3), 338-343.

[28] Ryan, D., Leukes, W. and Burton, S. 2006. Improving the bioremediation of phenolic wastewaters by Trametes versicolor. Bioresource Technology 98 (3), 579-587.

[29] Nakamoto, S. and Machida, N. 1992. Phenol removal from aqueous solutions by peroxidase catalyzed reaction using additives. Water Research 26, 49-54.

[30] Rodriguez, E., Numero, O., Guillen, F., Martinez, A. T., and Martinez, M. J. 2004. Degradation of phenolic and non-phenolic aromatic pollutants by four Pleurotus species: the role of laccase and versatile peroxidase. Soil Biology and Biochemistry 36 (6), 909-916.

[31] Gaitan, I. J., Medina, S. C., González, J. C., Rodríguez, A., Espejo, Á. J., Osma, J. F., Sarria, V., AlmécigaDíaz, C. J. and Sánchez, O. F. 2011. Evaluation of toxicity and degradation of a chlorophenol mixture by the laccase produced by Trametes pubescens. Bioresource Technology 102 (3), 3632-3635.

[32] Jones K. H., Trudgill P. W. and Hopper D. J. 1995. Evidence of two pathways for the metabolism of phenol by Aspergillus fumigates. Archives of Microbiology 163, 176-181.

[33] Joshi D. K. and Gold M. H. 1994. Oxidation of dibenzo-p-dioxin by lignin peroxidase from the basidiomycete Phanerochaete chrysosporium. Biochemistry 33 (36), 10969-10976.

[34] Reddy G. V. B. and Gold M. H. 2000. Degradation of pentachlorophenol by Phanerochaete chrysosporium: intermediates and reations involved. Microbiology 146, 405-413.

[35] Steiert, J. G. and Crawford, R. L. 1985. Microbial degradation of chlorinated phenols. Trends in Biotechnology 3 (12), 300-305. 